\title{
Corrosion Behaviors of Copper Exposed to an Urban Atmosphere
}

\author{
Ye Wan", Haixiao Zhang, Yanbo Li, Xiumei Wang, Fan Zhaorong, Xu Zhu
}

School of Materials Science and Engineering, Shenyang Jianzhu University, Shenyang 110168, China *E-mail: ywan@sjzu.edu.cn

doi: $10.20964 / 2018.07 .10$

Received: 27 February 2018 / Accepted: 21 April 2018 / Published: 5 June 2018

Copper was exposed for a total period of six months in an urban atmosphere, Shenyang site of China. The corrosion data of the exposed copper were collected for monthly intervals. The products and the corrosion amounts accumulated on the exposed copper have been investigated by mass loss, scanning electron microscopy, X-ray diffraction and coulometric reduction. The corrosion loss calculated from the reduction charges were compared with mass loss from the weight technique. The primary corrosion products found on field-exposed samples were copper oxides. For shorter exposure, such as no more than one month, the corrosion products were composed of $\mathrm{Cu}_{2} \mathrm{O}$ and $\mathrm{CuO}$. For more than two month exposure, the chemical components were mainly $\mathrm{Cu}_{2} \mathrm{O}$ and $\mathrm{CuO}$, and $\mathrm{Cu}_{2}(\mathrm{OH})_{3} \mathrm{Cl}$ and $\mathrm{Cu}_{2} \mathrm{~S}$ were also observed on the surface of the field exposed copper. The corrosion mechnisms of copper at Shenyang site are proposed as well.

Keywords: Copper; Atmospheric corrosion; Field exposure; Copper oxides; Coulomtric reduction

\section{FULL TEXT}

(C) 2018 The Authors. Published by ESG (www.electrochemsci.org). This article is an open access article distributed under the terms and conditions of the Creative Commons Attribution license (http://creativecommons.org/licenses/by/4.0/). 